\title{
A CONSTRUÇÃO DA AQUISIÇÃO E DA PRÁTICA DE PRODUÇÃO ORAL NA FORMAÇÃO DOCENTE EM FLE
}

Priscila Rodrigues Cardoso Fonseca Mestre em Letras - Linguística - pela Universidade do Estado do Rio de Janeiro (UERJ) priscila.prcf@gmail.com

\section{RESUMO}

Este trabalho tem por finalidade ser uma pesquisa-ação que objetiva oferecer dispositivos que façam os professores repensarem suas práticas docente. Assim, pretende-se apresentar o processo atual da aquisição e da prática de Produção Oral em docentes de instituições privadas de ensino de Francês como Língua Estrangeira (doravante FLE) do estado do Rio de Janeiro. Ademais, há o intuito de identificar e estruturar as principais dificuldades dos professores em seu percurso de formação, tendo como fontes teóricas a Sociolinguística e a didática de ensino de FLE. A coleta de dados dá-se mediante questionários de múltiplas escolhas e aplicação de entrevistas. Esta investigação tem como norte responder às seguintes questões: quais são os principais fatores ligados à aquisição da Produção Oral por parte dos educadores? Qual é o papel da universidade na sua formação? Como é processada a aprendizagem da L.E. no professor? Como esse processo influencia na sua prática?

Palavras-chave: aquisição de linguagem; FLE; produção oral; prática docente; formação de professores.

\section{RÉSUMÉ}

Ce travail a le but d'être une rechercheaction qui propose offrir des dispositifs qui permet aux enseignants de repenser leurs pratiques pédagogiques. Ainsi, ce travail vise à présenter le processus actuel d'acquisition et de pratique de la production orale chez les enseignants d'établissements privés d'enseignement de français langue étrangère (FLE) dans l'état de Rio de Janeiro. En plus, il y a I'intention d'identifier et de structurer les principales difficultés des professeurs dans son parcours de formation, en s'appuiant sur un matériel théorique construit à partir des lectures des sources théoriques de la Sociolinguística et de la didactique du FLE. La collecte des données se fait à travers des questionnaires à choix multiples et de l'application des interviews. Cette recherche vise à répondre aux questions suivantes: quels sont les principaux facteurs liés à l'acquisition de la production orale par les éducateurs? Quel est le rôle de l'université dans sa formation? Comment est l'apprentissage de L.E. chez les l'enseignant ? Comment ce processus influence-t-il leurs pratique?

Mots-clés: acquisition du langage; FLE; production orale; pratique et enseignement; formation des enseignants. 


\section{Introdução}

A presente pesquisa nasceu da inquietação fomentada no momento em que entrei em sala de aula para começar a lecionar o francês como língua estrangeira (L.E.) durante a Graduação no curso de Letras - Português/Francês, da Universidade do Estado do Rio de Janeiro (UERJ), entre os anos de 2008 a 2013. Esse incômodo com o processo de aquisição de uma produção oral (doravante P.O.) satisfatória - para muitos, difícil e incompleto - intensificou-se no Curso de Pós-Graduação Lato Sensu de Ensino de Francês Língua Estrangeira, realizado também na UERJ, em 2014.

Com este estudo, percebi que ao se tratar da competência de P.O. no ensinoaprendizagem da Língua Francesa muito se discute com o foco no aluno. Entretanto, ao professor, parte fundamental deste processo, não era dada muita atenção, por considerar que este já possui tal competência "consolidada", esquecendo que o docente tem de se formar continuamente, sendo ele também um aluno; por isto, verifica-se que

a capacidade de investir em sua própria formação de se responsabilizar por uma aprendizagem que não se encerra na universidade, mas que se expande a diferentes momentos e áreas. É o conceito de professor-pesquisador-aprendiz em permanente formação que vem à tona (PIETRARÓIA; ALBUQUERQUE-COSTA, 2013, p. 8).

Com isso, o professor possui uma tripla função: a de ser concomitantemente professor, pesquisador e aprendiz. O cenário observado na pesquisa realizada em 2014 levou-me a procurar uma análise mais aprofundada sobre os fatores que influenciam negativamente a oralidade inserida na competência comunicativa, agora, com foco nos 
professores, uma vez que ao longo da minha vida acadêmica - como aluna e como professora - percebi que o professor possui vários papéis, tal Pozo afirma:

[...] todo professor tem de exercer muitas tarefas diferentes, tem de assumir vários personagens, num complicado exercício de multiplicação profissional.

\section{$[\ldots]$}

a) Do professor provedor, que proporciona aos alunos informação, fatos e dados, mas que também dá instruções ou administra prêmios e castigos. É o professor que tem a resposta que o aluno necessita.

b) Do professor modelo, que ilustra modos de comportamentos, atitudes ou habilidades motoras, através de seu comportamento atitudes ou habilidades. É o espelho em que os alunos olham para saber o que têm de fazer. Com muita frequência, é um papel mais implícito que explícito.

c) Do professor treinador, que fixa em detalhe o que os alunos devem fazer, quando, como e quanto, como um médico com seus pacientes. Fixa o tratamento e o aluno deve se limitar a cumpri-lo custe o que custar. É um papel complementar ao de provedor. Pode ser prover informação sem treinar em seu uso, mas não o contrário.

d) Do professor tutor ou guia, que deixa que os alunos assumam parte da responsabilidade de sua aprendizagem, mas depois que lhes fixou bem as metas e os meios para alcançá-los. O tutor diz o que é preciso fazer e como, mas deixa que os alunos organizem sua própria pratica, que ele acompanha e regula. Pergunta aos alunos em vez de lhes dar respostas.

e) Do professor assessor ou diretor de pesquisa, que deixa que os alunos façam seus próprios objetivos concretos e planejem sua própria aprendizagem, a partir de um marco geral previamente estabelecido (POZO, 2002, p. 92).

Ademais, acrescento que é necessário adicionar à lista acima a função primeira do professor, que é o "professor aluno". A exemplo de Pimentel (1994, p. 16), que declara “minha atuação norteou-se sempre pela ideia de que a formação do professor se dá enquanto ensina. Não posso deixar de afirmar que me eduquei educando". Esse é o 
primeiro personagem, é aquele que se encontra nas salas das universidades, é o futuro professor.

Sabe-se, consequentemente, que todo docente já foi, e continua sendo, aluno, e que também já experienciou o processo de aquisição de uma L.E.; todavia, percebe-se que, além dos fatores didáticos - como a escolha da metodologia, dos objetivos do curso, entre outros -, há uma forte presença de fatores psicológicos e de formação acadêmica enquanto elementos dificultadores do ensino da produção oral.

Talvez seja este um dos aspectos mais deprimentes da formação e da atuação do professor, na medida em que tende a reproduzir-se ininterruptamente, se não the opormos firme resistência: matérias e aulas sucedem-se como se nenhuma relação existisse entre as mesmas, como unidades estanques de um mosaico desarticulado. $[\ldots]$

Talvez não haja outro lugar, fora da escola, em que seja tão grande a distância entre o dizer e o fazer (PILETTI, 2016, p. 262).

O professor é aquele que já ocupou - e o bom docente continua sempre ocupando - a cadeira de aluno; é aquele que se interessa em melhorar sua performance a partir de suas experiências como tal e, principalmente, como aluno; poucas são as profissões que permitem essa dupla função/reflexão.

Logo, a pesquisa com foco nos docentes abre caminhos para entender a qualidade e os problemas que envolvem o ensino de FLE nas salas de aula, possibilitando retornar à raiz do processo, a formação docente. Nas palavras de Bortoni-Ricardo,

o docente que consegue associar o trabalho de pesquisador a seu fazer pedagógico, tornando-se um professor pesquisador da sua própria prática ou das práticas pedagógicas com as quais convive, estará no caminho de aperfeiçoar-se 
profissionalmente, desenvolvendo uma melhor compreensão de suas ações como mediador de conhecimentos e de seu processo interacional com os educandos. Vai também ter uma melhor compreensão do processo de ensino e de aprendizagem (2008, p. 32-33).

Sendo assim, esta pesquisa tem o intuito de lançar um olhar sobre os principais pontos ligados à formação do professor de FLE. Para tanto, pretende-se responder à questão: Quais são os principais fatores ligados à aquisição da P.O. por parte dos educadores?

\section{O sociointeracionismo}

Ao estudar sobre o processo de ensino-aprendizagem tendo um olhar voltado para as relações sociais que constituem os sujeitos na sala de aula, não se pode deixar de recorrer a Vygotsky e sua teoria do sociointeracionismo.

A proposta teórica de Vygotsky expressa que

a natureza humana é, desde o início, essencialmente social: é na relação com o próximo, numa atividade prática comum mediada pelos signos e instrumentos, que os homens se constituem e se desenvolvem como tais (PALANGANA, 2015, p. 155).

Para ele, as interações sociais influenciam muito no processo de ensinoaprendizagem, não somente nas crianças, mas, deslocando esse conceito para o grupo analisado - professores de FLE -, sabe-se que o contexto e o contato sociais influenciam o modo como se aprende e como se ensina. 
Deslocando o foco para esta pesquisa, o contexto e contato sociais são, respectivamente, o processo de formação em si - suas experiências acumuladas ao longo de sua vida como aluno e professor - e as relações entre os professores que o ensinaram, seus colegas de turma, cursos, seminários, e/ou todo e qualquer contato com o seu objeto de ensino, neste caso, a Língua Francesa. Na competência de P.O., esses dois quesitos misturam-se, visto que é pela atividade da fala que se estuda e melhora a própria oralidade. A título de exemplificação do exposto, Palangana (2015, p. 155) nos traz mais uma postura de Vygotsky, a qual expressa que "a fala é, desde o estágio mais primitivo, socializada, e sua função primordial, tanto nas crianças como nos adultos, é a comunicação, o contato social".

\section{A pesquisa em formação de professores}

Nota-se, cada vez mais, que no Brasil a profissão docente sofre uma desvalorização tamanha por parte do poder público; mesmo o professor que trabalha na rede privada de ensino de FLE também é atingido por esse descaso com a formação de professores, uma vez que nas faculdades - sejam públicas ou privadas - não há grandes investimentos em pesquisas nos campos educacional e pedagógico, levando, desse modo, as ciências sociais e os pesquisadores desta área a uma desmotivação. 
Tabela 1 - Produtividade em pesquisa do CNPq

16- Número de bolsas de produtividade em pesquisa do CNPq, de doutores e relações segundo área do conhecimento - 2000, 2002, 2004, 2006, 2008, 2010

\begin{tabular}{|c|c|c|c|c|c|c|}
\hline \multirow{2}{*}{ Grande área } & \multicolumn{6}{|c|}{ № de bolsas-ano (BPQ) } \\
\hline & 2000 & 2002 & 2004 & 2006 & 2008 & 2010 \\
\hline Ciências Agrárias & 1.062 & 1.114 & 1.189 & 1.278 & 1.399 & 1.821 \\
\hline Ciências Biológicas & 1.272 & 1.363 & 1.504 & 1.582 & 1.652 & 2.085 \\
\hline Ciências da Saúde & 713 & 771 & 883 & 947 & 1.091 & 1.385 \\
\hline Ciências Exatas e da Terra & 1.505 & 1.558 & 1.619 & 1.758 & 1.959 & 2.498 \\
\hline Ciências Humanas & 851 & 873 & 989 & 1.069 & 1.171 & 1.481 \\
\hline Ciências Sociais Aplicadas & 442 & 455 & 517 & 556 & 620 & 785 \\
\hline Engenharias & 1.269 & 1.324 & 1.413 & 1.513 & 1.660 & 2.263 \\
\hline Linguística, Letras e Artes & 298 & 308 & 338 & 369 & 413 & 485 \\
\hline Todas as grandes áreas & 7.413 & 7.765 & 8.451 & 9.073 & 9.965 & 12.804 \\
\hline
\end{tabular}

Fonte: ROCHA; DAHER (2015). Disponível em:

<cnpq.br/documents/10157/568debbd-c058-44df-8a8b-1af1b9367e42>. Acesso em: 12 jun. 2017.

Isso provoca no professor a sensação de estar sozinho na tarefa de educar, deixando-o, ainda, sem tempo para investir em si próprio, dada a grande quantidade de trabalho, bem como a falta de boa remuneração. Logo, muitas vezes o docente sente-se perdido, posto que, de um lado, tenta suprir a necessidade de seus alunos e, de outro, cumprir as exigências da instituição na qual trabalha e, por fim, suas exigências pessoais, no campo da formação continuada de natureza linguística e reflexiva.

Por conseguinte, a pesquisa em educação, mais especificamente com foco no professor e em sua formação, é uma forma de juntar forças para juntos repensar o papel docente, (res)significar sua prática e alçar novos caminhos. Como resumiu Celani (2003, p. 22),

esse objetivo implica necessariamente em um conceito de educação continua que vai muito além da mera participação esporádica em cursos de férias, seminários ou oficinas. A educação continua não pode ser vista em termos apenas de produtos resultados de cursos, por exemplo -, mas sim deve ser entendida em termos de um processo que possibilita ao professor educar-se a si mesmo, à medida que caminha 
em sua tarefa de educador. É uma forma de educação que, não tendo data fixa para terminar, permeia todo o trabalho do indivíduo. Eliminando, consequentemente, a ideia de um produto acabado - por exemplo, dominar uma certa técnica -, em um momento ou período determinados.

Além disso, é preciso fomentar nos professores - seja na graduação, seja nas pósgraduações - a ideia de que sua prática e formação não se encerram ao final do curso universitário, que a retomada do seu papel de aluno deve sempre ser feita, para que não se sinta depois o peso da desatualização, da cobrança externa e interna, do papel de mero reprodutor de práticas, por eles mesmos, questionadas e até ultrapassadas.

Por conseguinte, a falta de oportunidade de colocação em sala de aula de suas reflexões não permite que o professor-aprendiz construa sua autonomia de atuação, o que interfere diretamente na sua prática. Busca-se nesta pesquisa que o professor consiga realizar na prática a teorização que o envolve. Ser autônomo é ultrapassar a discussão teórica para que se possa aplicar na ação o que foi dito, pensado e refletido.

Portanto, esse cenário demonstra que a pesquisa voltada para a formação do docente é ainda uma das áreas mais carentes no Brasil. De acordo com Abrahão (2012, p. 458), a ideia de formação do professor ainda está vinculada às concepções positivistas e tradicionais de ensino-aprendizagem, de como se aprende e como se ensina. Essa perspectiva reflete-se na forma como esses cursos voltados para a educação de professores são pensados:

Nos cursos de formação de professores de língua há o predomínio de treinamento de técnicas especificas, consideradas ideais, precedidas da exposição e "transmissão" de conhecimento, gerados pelas pesquisas em Linguística Aplicada e em Aquisição de Línguas. 
Para transformar toda essa conjuntura, é preciso

criar múltiplas oportunidades para que os alunos professores participassem em um conjunto de atividades relacionadas ao ensino, para criar múltiplas oportunidades de mediação estratégica quer pelos colegas quer pelo professor formador (ABRAHÃO, 2012, p. 469-470).

\section{Perfil metodológico para análise do corpus}

A escolha metodológica qualitativa ou interpretacionista vai de encontro ao modelo quantitativo ou positivista de pesquisa, que prima pelo que pode ser controlado, quantificável e traduzido em números. Entretanto, para os interpretacionistas, os estudos que possuem a atividade humana - intimamente ligada ao contexto social e à interação têm de ser tratados de forma interativa e interpretativa, posto que é interagindo e interpretando o mundo e suas relações que o homem constrói sentidos para sua existência. Conforme Chizzote (2003, p. 230),

a posição social do autor da pesquisa, a onipotência descritiva do texto cientifico, a transição objetiva da realidade são postas em questão: o pesquisador está marcado pela realidade social, toda observação está possuída de uma teoria, o texto não escapa a uma posição no contexto político e a objetividade está delimitada pelo comprometimento do sujeito com sua realidade circundante.

No caso deste estudo, pretende-se dar voz aos professores de FLE por também assumirem o papel de aluno. Pelo fato de a Língua Francesa não ser sua língua materna, estes devem estar em constante formação/atualização, conscientes do processo de ensino-aprendizagem do qual são duplamente participantes: ao ensinarem e ao 
aprenderem. Pretende-se analisar como o processo de formação docente desenvolve-se para o próprio, em especial com relação à P.O., para, assim, entender e ajudar os docentes a refletir sobre sua formação e construção.

Deste modo, em concordância com os procedimentos técnicos, a metodologia orientadora escolhida trata-se da pesquisa-ação, dado que:

A pesquisa-ação, quando implementada ainda na fase de formação do professor, permite a ele refletir sistematicamente sobre os conflitos inerentes a uma posição complexa como a que ocupa, uma vez que o licenciando caminha no campo limítrofe entre a docência e a discência.

$[\ldots]$

A pesquisa-ação estaria presente como metodologia de investigação que permitiria ao futuro professor compreender melhor o contexto em que atua e sistematizar esses conflitos para que eles não sejam apenas um fator angustiante, mas sim um avanço em sua formação como professor-pesquisador (LEFFA, 2008, p. 305).

Segundo Moita Lopes (1996), somente a pesquisa-ação nos permite tamanha participação, uma vez que tanto esta pesquisadora quanto os participantes estão envolvidos no contexto da sala de aula, lidando com a árdua tarefa de aprender e ensinar uma L.E. Com isso, todos estão dispostos a participar e cooperar para encontrar a solução ou soluções às suas inquietações.

Ainda consoante os objetivos deste estudo, Thiollent (1986), um dos estudiosos da técnica de pesquisa chamada pesquisa-ação, afirma que

querem pesquisas nas quais as pessoas implicadas tenham algo a "dizer" e a "fazer". Não se trata de simples levantamento de dados ou de relatórios a serem arquivados. Com a pesquisa-ação os pesquisadores pretendem desempenhar um papel ativo na própria realidade dos fatos observados (p. 16). 
Logo há aqui um caráter reflexivo, posto que, ao analisar o processo de aquisição da oralidade nos docentes, possibilita-se aos professores - ainda em formação e aos já formados - um panorama deste processo. Com a identificação e a posterior reflexão tais docentes podem estar mais conscientes do seu papel, das suas dificuldades e certezas, fomentando em si mesmos e em seus alunos - por meio da troca de experiência e informações - caminhos para alcançar uma competência de produção oral satisfatória para o ouvinte, e ainda mais para seu locutor.

\section{Geração de dados e constituição do corpus}

Para a análise dos dados, procedeu-se a uma pesquisa de campo, realizada durante o segundo semestre de 2016. Aplicou-se um questionário online pela plataforma Google contendo 34 perguntas, divididas entre perguntas fechadas, de múltipla escolha, e abertas, classificadas conforme Lakatos \& Marconi (2016, p. 187-189). Todas as perguntas foram respondidas por 13 professores de três diferentes instituições privadas de ensino de FLE no Estado do Rio de Janeiro. É importante frisar que, apesar do caráter inicialmente quantitativo da coleta de dados, o questionário online serviu apenas como piloto para a construção da etapa das entrevistas, ainda em construção.

Após esta fase, e a partir das respostas observadas nos questionários, proceder-seá, no segundo semestre de 2017, à realização de entrevistas individuais semiestruturadas.

\section{Participantes}


Apresenta-se, na tabela a seguir, uma breve descrição profissional de cada um dos participantes, obtidas pelos questionários online. Essas respostas possibilitam um melhor entendimento sobre as questões relatadas pelos docentes em suas experiências como professores e também alunos envoltos no contexto de ensino de FLE, colaborando para o estudo.

Tabela 2 - Perfil dos participantes da 1a etapa: questionários

\begin{tabular}{|c|c|c|c|c|c|}
\hline Particip. & Sexo & $\begin{array}{c}\text { Formação } \\
\text { profissional }\end{array}$ & $\begin{array}{c}\text { Idade média } \\
\text { dos alunos } \\
\text { (anos) }\end{array}$ & $\begin{array}{c}\text { Níveis (CECR') } \\
\text { que leciona }\end{array}$ & $\begin{array}{c}\text { Anos como } \\
\text { professor } \\
\text { FLE? }\end{array}$ \\
\hline P1 & Masc. & Mestrado & 25 & A1 a B1 & 4 \\
\hline P2 & Fem. & Especialização & 30 & B1 & 8 \\
\hline P3 & Fem. & Mestrado & 25 a 50 & A1 a, B2 & 11 \\
\hline P4 & Fem. & Especialização & 16 a 35 & A1 a B1 & 6 \\
\hline P5 & Fem. & Especialização & $\begin{array}{c}\text { Jovens e } \\
\text { adultos }\end{array}$ & A1 a B1 & 6 \\
\hline P6 & Fem. & Especialização & 25 & A1 a B1 & 6 \\
\hline P7 & Fem. & Graduação & Adultos & A1 a B2 & 5 \\
\hline P8 & Fem. & Mestrado & $\begin{array}{c}\text { Adultos (20 a } \\
50)\end{array}$ & A1 a B1 & 4 \\
\hline P9 & Fem. & Doutorado & Entre 14 e 60 & A1 a, B2 & 36 \\
\hline P10 & Masc. & Graduação & 25 & A1 a B2 & 4 \\
\hline P11 & Fem. & Mestrado & 15 & A1 a B2 & 10 \\
\hline P12 & Fem. & Doutorado & 20 & A1 a, C2 & 15 \\
\hline P13 & Fem. & Doutorado & 20 & A2 e C1 & 15 \\
\hline
\end{tabular}

FONTE: Tabela elaborada pela pesquisadora.

\section{Análise do corpus e resultados}

Para maiores resultados e conclusões é preciso aprofundar o estudo no processo de ensino-aprendizagem de uma LE para os docentes de $F L E$, o que será realizado na 
segunda etapa: as entrevistas semiestruturadas. Utilizar-se-á, nesta análise, apenas as perguntas que contemplaram, mais diretamente, o percurso da formação docente.

Com o intuito de responder às questões colocadas no início deste estudo, começase a análise com a tabela com o perfil da formação profissional dos 13 docentes que participaram da primeira fase da coleta de dados, isto é, do questionário online:

Gráfico 1 - Formação docente dos participantes

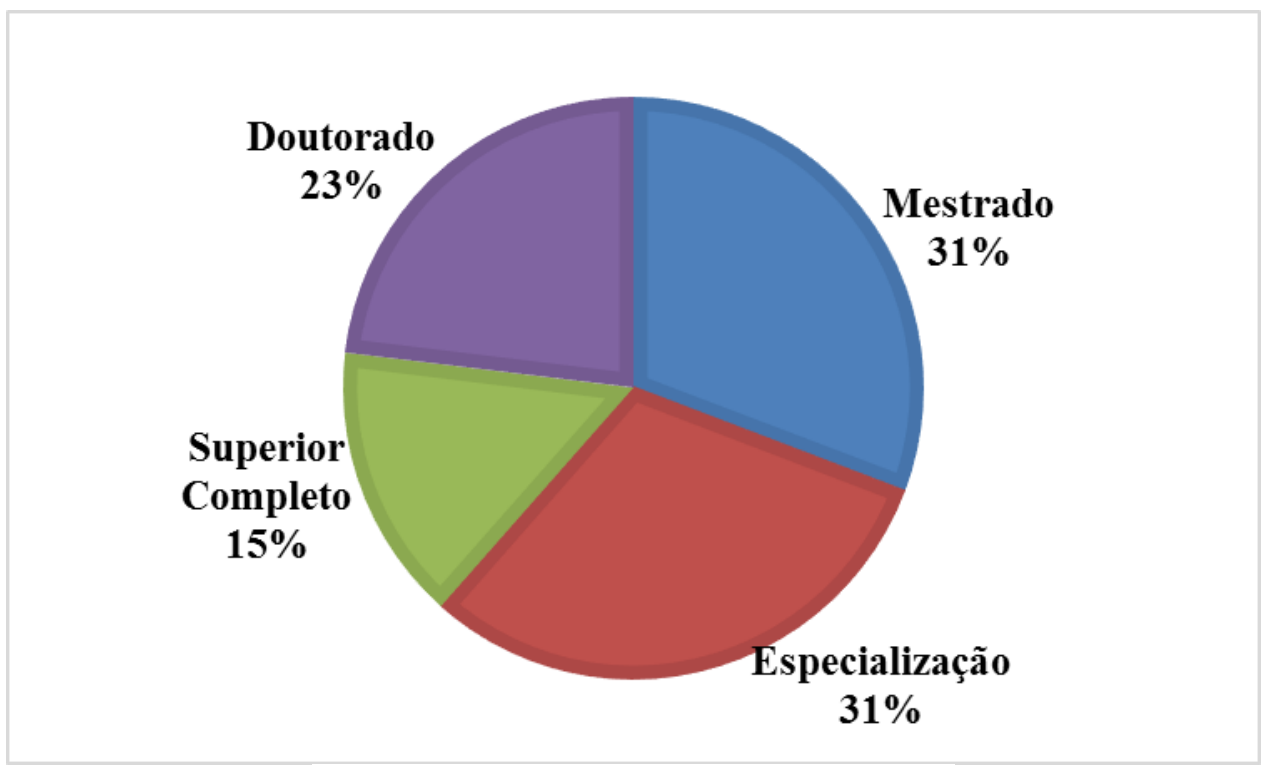

FONTE: Gráfico elaborado pela pesquisadora.

Percebe-se que há uma diferenciação na formação entre os que já possuem doutorado, mestrado, especialização e graduação completa. Como consequência dessa diversidade, acredita-se que a análise contemple diferentes níveis de aprendizagem e experiências profissionais.

$\mathrm{Na}$ pergunta no 26 do questionário online, "Durante sua graduação, qual a intensidade de trabalho com Produção Oral nas aulas?", nove docentes afirmaram ter feito este trabalho "na maior parte do tempo", em detrimento das outras opções, conforme gráfico abaixo: 
Gráfico 2 - Intensidade do trabalho com a PO nas aulas

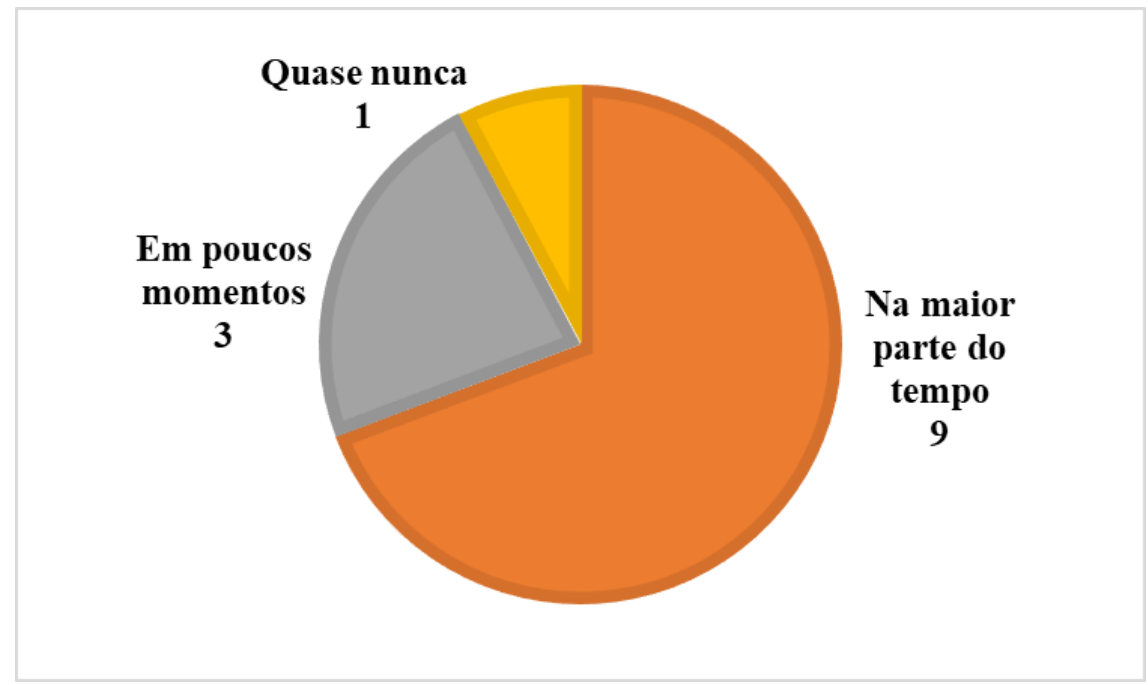

FONTE: Gráfico elaborado pela pesquisadora.

Ressalta-se que uma das opções da pergunta no 26 era o trabalho de P.O. durante todo o tempo de aula, o que não foi marcado por nenhum dos professores participantes da pesquisa. Tal pergunta tinha por objetivo saber se os participantes se expressavam oralmente, por meio de exercícios fechados e/ou controlados ou através da conversação livre em sala de aula enquanto alunos da graduação. Esse resultado contrasta com as respostas dadas na pergunta no 27 - "Durante sua graduação, a apropriação da fala em sala de aula era majoritariamente:" -, na qual, dos 13 docentes analisados, 12 afirmaram ser essa apropriação do professor.

A partir do resultado, percebe-se um contraste nas respostas das perguntas de $n$ 은 26 e 27; visto presumir que, se durante a graduação a apropriação da fala foi majoritariamente do professor, os docentes em formação pouco trabalhavam a oralidade. De acordo com os dados, deduz-se que, para os participantes, o trabalho com a oralidade não estava necessariamente ligado à produção oral deles próprios e à sua formação, mas, sim, ao ouvir a fala do professor - o que seria, neste caso, a competência 
de compreensão oral. Assim, a expressão oral ficaria restrita a exercícios conduzidos e determinados para este fim.

Nesse caminho, a pergunta no 28, "Durante sua graduação, havia/há interação na L.E. entre os seus colegas de turma?", objetiva analisar o papel da interação na aprendizagem com a produção oral durante o processo de formação docente. Para Vygotsky (1995), a interação é parte fundamental no processo de aprendizagem, posto que "a função primordial da fala é a comunicação, o intercâmbio social" (p. 5). Em seguida, a pergunta no 29, "Você se sentiu preparado para lecionar ao sair da universidade?", procura analisar qual é o sentimento do encerramento de um ciclo de formação para o docente.

Tabela 3 - Perguntas sobre interação e autoavaliação na visão dos professores

\begin{tabular}{|l|c|c|}
\hline Participantes & $\begin{array}{c}\text { Durante sua graduação, havia/há } \\
\text { interação na LE entre os seus } \\
\text { colegas de turma? }\end{array}$ & $\begin{array}{c}\text { Você se sentiu preparado para } \\
\text { lecionar ao sair da } \\
\text { universidade? }\end{array}$ \\
\hline P1 & Sim & Sim \\
\hline P2 & Não & Não \\
\hline P3 & Sim & Sim \\
\hline P4 & Não & Não \\
\hline P5 & Não & Sim \\
\hline P6 & Sim & Não \\
\hline P7 & Sim & Sim \\
\hline P8 & Não & Sim \\
\hline P9 & Sim & Não \\
\hline P10 & Não & Sim \\
\hline P11 & Não & Sim \\
\hline P12 & Não & Não \\
\hline P13 & Sim & Não \\
\hline
\end{tabular}

FONTE: Tabela elaborada pela pesquisadora. 
Observa-se acima que metade dos docentes afirmaram ter interação. Para uma maior avaliação da interação no processo de produção oral, a fase futura das entrevistas será importante para verificar como se desenvolve a relação com os colegas em sala de aula. Vê-se, ainda, que metade deles afirmou se sentir preparado, e outra metade não; contudo, não houve relação direta dos que disseram não ter tido relação com o sentimento de se sentir preparado para lecionar. Assim, não é possível estabelecer um paralelo entre o papel da interação como fator preponderante no processo de oralidade durante a formação docente, como esperado.

A pergunta "O que faltou/falta na sua formação?" era aberta, possibilitando aos professores relatar o que foi um elemento dificultador na sua formação e consequente prática. A partir das respostas colhidas, observa-se que o esclarecimento sobre a prática real de ensino foi a mais relatada segundo os docentes. Entretanto, na pergunta "Durante sua formação, você teve/tem direcionamento de como repensar sua prática docente?", todos afirmaram que sim. Isso permite concluir que, em termos teóricos, a formação do professor de língua estrangeira, especialmente de francês, é satisfatória para os docentes. Contudo, é preciso trabalhar melhor essa relação entre teoria e prática.

A pergunta no 33, "No seu cotidiano, há troca de informação com outros profissionais da área?", retoma o tópico da interação, sendo possível perceber que todos os professores afirmaram trocar informações seus colegas de profissão.

Por fim, a pergunta "O que você, como professor de FLE (Français comme Langue Étrangère) sente mais dificuldade em sua formação/atuação profissional?" visa saber quais são as inquietações e dificuldades dos docentes de FLE durante sua atuação e formação. Importante frisar que nessa questão os docentes podiam marcar mais de uma opção. Assim em termos absolutos, de acordo com o gráfico a seguir, tem-se: 
Gráfico 3 - Dificuldades dos professores durante sua formação

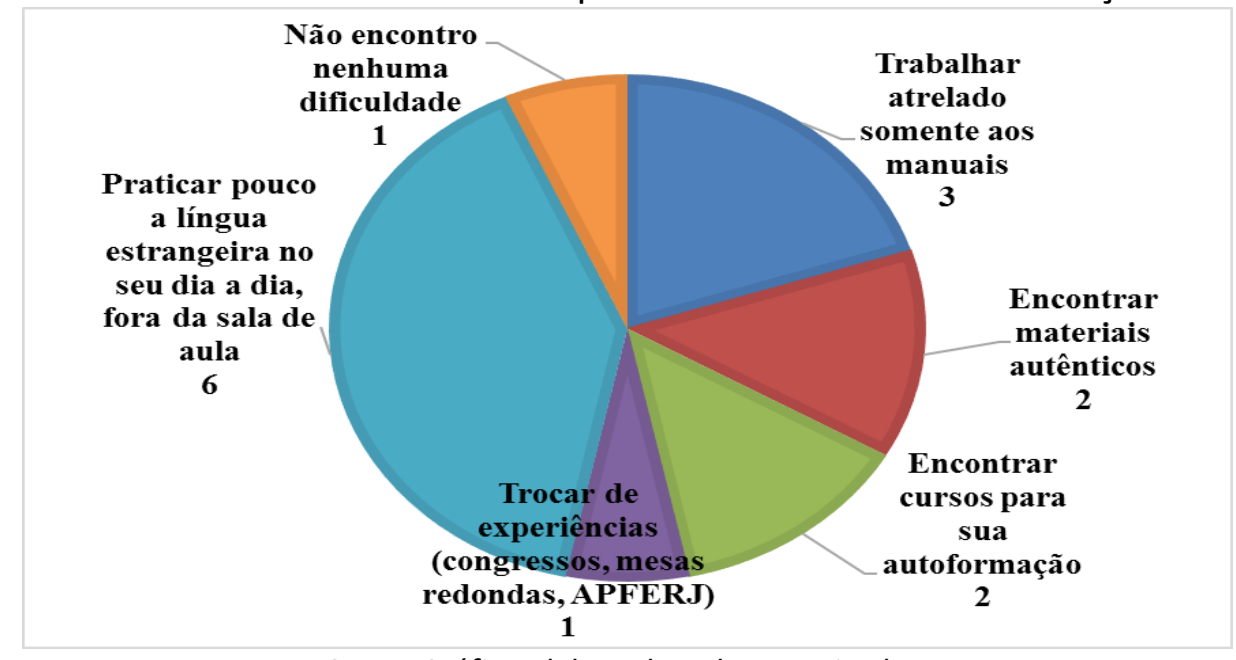

FONTE: Gráfico elaborado pela pesquisadora.

A partir dos resultados, observa-se que a opção de praticar pouco a língua foi a que recebeu mais votos, resultado já esperado por tratar da produção oral em uma língua estrangeira. Ademais, sabe-se que a autoformação e a formação contínua são essenciais para a atualização do docente a respeito de tudo o que envolve o ensino-aprendizagem, tais como novas metodologias e práticas. Assim, todas as outras opções que apareceram como resposta devem ser tratadas com atenção, a fim de tornar o fazer docente fora da sala de aula mais satisfatório para o profissional nele envolvido.

\section{Conclusão}

Embora esta pesquisa seja um estudo em construção e de abrangência limitada, por tratar-se de analisar o comportamento de 13 participantes na primeira fase, não cabendo a construção de grandes generalizações, permite que algumas considerações sejam feitas para um melhor entendimento do processo de ensino-aprendizagem de um docente em LE. É mister salientar que o objetivo deste estudo não é apresentar verdades absolutas, por ser uma pesquisadora em um contexto aplicado, no qual "a validade da investigação humana 
recorre à possibilidade de se traduzir a experiência humana em um texto" (SMITH, 1993; TIERNEY \& LINCOLN, 1997 apud CHIZZOTTI, 2003, p. 231).

Na tentativa de responder à pergunta inicialmente colocada - Quais são os principais fatores ligados à aquisição da P.O. por parte dos educadores? -, conclui-se que a aprendizagem da P.O. é um processo extremamente individual e dependente de múltiplos fatores. Vê-se que, com relação à P.O., apesar desta competência ser trabalhada quase todo o tempo, os docentes sentem a necessidade de mais prática; talvez devido ao fato de, ainda durante sua formação acadêmica, a fala ser majoritariamente do professor.

Não se pôde concluir se a interação é preponderante, durante a graduação, para uma aprendizagem satisfatória da oralidade. Entretanto, durante a vida profissional, acredita-se que ela seja importante para a manutenção da formação do docente, visto que todos afirmaram que, após formados, trocam experiências com outros profissionais da área. Assim, é preciso, futuramente voltar ao contexto da sala de aula da universidade a fim de questionar se o ambiente acadêmico propicia e incentiva essa troca/contato/interação entre os professores em formação.

Com relação ao direcionamento da prática docente oferecido pelo ensino universitário e o que ainda falta nesse ensino, na visão dos próprios docentes, pode-se concluir que tal situação, em sua maioria, é provocada pela, ainda, pequena e pouco trabalhada autonomia, que o professor ainda não está habituado a exercer. Durante sua formação acadêmica, o futuro professor é incentivado a pensar sobre sua prática, sobre as teorias e metodologias que a embasam e a influenciam, mas é dada pouca atenção para a efetiva prática.

O Gráfico 3 comprova esse fundamento, dado que ao tratar de oralidade sua prática no cotidiano é sempre importante, seja dentro ou fora da universidade. Desta forma, importa frisar que professores e instituições devem sempre buscar novas formas de 
trabalhar a P.O. em FLE, uma vez que cada aluno possui um mecanismo de aprendizado diferente, bem como prezar pela variedade e pelo ecletismo das metodologias. Além disso, as instituições de ensino devem fornecer ao professor meios de trabalhar calma e livremente em cada turma, com cada estudante, já que

la finalité de l'enseignement des langues, aujourd'hui déclarée, est de faire de l'apprenant un individu plurilangue, au minimum capable de se débrouiller à l'étranger dans les situations les plus courantes de la vie quotidienne, et, ainsi, de permettre une meilleure compréhension et communication entre les peuples (TAGLIANTE, 2006, p. 26) ${ }^{\mathrm{ii}}$.

\section{Referências}

BRASIL. CNPQ. Estatísticas e indicadores da pesquisa no Brasil. Disponível em: <http://cnpq.br/documents/10157/f653f40d-8a19-468a-aa8f-bb3ac557e32c>. Acesso em: 12 jun. 2017.

CELANI, M. A. A. (Org.). Professores e formadores em mudança: relato de um processo de reflexão e transformação da prática docente. Campinas, SP: Mercado de Letras, 2002.

CHIZZOTE, A. A pesquisa qualitativa em ciências humanas e sociais: evolução e desafios. Revista Portuguesa de Educação, Braga, Portugal, v. 16, n. 2, p. 221-236, 2003.

FONSECA, P. R. C. Produção oral: uma análise do cenário atual da produção oral em instituições privadas de ensino em FLE do estado do Rio de Janeiro. 2015. 40 p. Monografia (Especialização em Ensino de Francês Língua Estrangeira) - Instituto de Letras, Universidade do Estado do Rio de Janeiro, Rio de Janeiro.

LAKATOS, E. M.; MARCONI, M. A. Fundamentos de metodologia científica. 7 ed. São Paulo: Atlas, 2016.

LEFFA, V. J. (Org.). O professor de línguas estrangeiras: construindo a profissão. 2 ed. Pelotas, RS: EDUCAT, 2008. 
MOITA LOPES, L. P. Oficina de Linguística Aplicada. São Paulo: Mercado de Letras, 1996.

PALANGANA, I. C.. Desenvolvimento e aprendizagem em Piaget e Vygotsky: a relevância do social. São Paulo: Summus, 2015.

PIETRARÓIA, C. M. C.; ALBUQUERQUE-COSTA, H. (Orgs.). Ensino de língua francesa em contexto(s). Série Enjeu. v. 1. São Paulo: Paulistana, 2013.

PILETTI, C. N. História da educação. São Paulo: Contexto, 2016.

PIMENTEL, M. G. O professor em construção. 4 ed. São Paulo: Papirus, 1998.

POZO, J. I. Aprendizes e mestres: a nova cultura da aprendizagem. Porto Alegre: Artmed, 2002.

ROCHA, D.; DAHER, D. C. Afinal, como funciona a Linguística Aplicada e o que ela pode se tornar?. D.E.L.T.A, São Paulo, v. 31-1, p. 105-141, 2015.

TAGLIANTE, C. La classe de langue. Paris: CLÉ International, 2006.

THIOLLENT, M. Metodologia da pesquisa-ação. São Paulo: Cortez, 1986.

VIEIRA ABRAHÃO, M. H. A formação do professor de línguas de uma perspectiva sociocultural. SIGNUM: Estudos da Linguagem, n. 15/2, p. 457-480, dez. 2012.

VYGOTSKY, L. S. Pensamento e linguagem. São Paulo: Martins Fontes, 1995.

\footnotetext{
'Cadre Européen Commun de Référence (Quadro Europeu Comum de Referência para as Línguas).

i" O objetivo do ensino de línguas, declarado atualmente, é fazer do aluno um indivíduo poliglota, capaz, ao menos, de se comunicar, no país estrangeiro, nas situações mais correntes da vida cotidiana, e, assim, permitir uma melhor compreensão e comunicação entre as pessoas. (tradução minha)
}

Recebido em 31 de julho de 2017. Aceito em 11 de setembro de 2018. 